\title{
Vegetation greenness response to water availability in northern China from 1982 to 2006
}

\author{
Fengtai Zhang ${ }^{1}$ and Youzhi An ${ }^{1,2}$ \\ ${ }^{1}$ Guizhou Education University, Guiyang 550018, China \\ ${ }^{2}$ Key Laboratory of Geographic Information Science, Ministry of Education, East China Normal University, \\ Shanghai 200241, China \\ Correspondence to: Fengtai Zhang (zhfthero@126.com)
}

Received: 4 March 2016 - Published in Solid Earth Discuss.: 23 March 2016

Revised: 16 May 2016 - Accepted: 18 May 2016 - Published: 28 June 2016

\begin{abstract}
Vegetation and moisture are two key factors of soil genesis and development. An evaluation of the relationship between satellite-observed normalized difference vegetation index (NDVI) data as a proxy for vegetation greenness and water availability (rainfall and soil moisture) can greatly improve our understanding of how vegetation greenness responds to water availability fluctuations. Using Sen and Pearson's correlation methods, we analyzed the spatiotemporal variation of vegetation greenness for both the entire year and the growing season (GS, 4-10) in northern China from 1982 to 2006. Although vegetation greenness and soil moisture during the study period changed significantly for the entire study area, there was no change in rainfall. Linear correlation analysis between NDVI and rainfall revealed higher correlations using data for all seasons. Higher correlations for NDVI and soil moisture were obtained using growing season data. This study highlights how strongly vegetation greenness responds to water availability dynamics, especially in the growing season period.
\end{abstract}

\section{Introduction}

Water availability is generally assumed to be one of the most important parameters for vegetation greenness (Zhang et al., 2010; Huber et al., 2011; Niu et al., 2015). The soil system is the key component of the Earth system as a control for the biological, hydrological, and geochemical cycles (Keesstra et al., 2012; Smith et al., 2015; Decock et al., 2015; Brevik et al., 2015; Berendse et al., 2015). Soil genesis depends on factors such as vegetation cover and soil moisture, which are also related to the interaction with other factors and processes, including the human interferences with natural processes (Keesstra et al., 2016a). Vegetation controls the soil erosion processes (Vaezi et al., 2016) and interacts with the plant dynamics (Bochet et al., 2015), and soil moisture is a key factor of vegetation development (Lucas-Borja et al., 2016). Satellite-derived normalized difference vegetation index (NDVI) data, which potentially provide much greater spatial and temporal coverage, have recently played an important role in investigating the relationship between NDVI and water availability (rainfall and soil moisture) around the world. Soil genesis and development is to a great extent determined by the vegetation as a control for soil erosion and contribute to the biological diversity of the soils (Cerdà, 1998; Yu and Jia, 2014; Beyene, 2015; Laberge et al., 2015; Keesstra et al., 2016b). In arid and semi-arid regions, particularly in northern China, rainfall is a major factor controlling vegetation growth, and affect many soil parameters and properties (Hewelke et al., 2014; Yu et al., 2015). Much work has been done studying the relationship between vegetation greenness and rainfall (Hellden and Tottrup, 2008; Huang et al., 2012; Mu et al., 2012). Previous studies have relied on either the annual (growing season) or seasonal temporal scale to determine the interannual variation in NDVI and rainfall (Hellden and Tottrup 2008; Huang et al., 2012). Most studies on the greenness (NDVI as a proxy) and rainfall relationship in northern China have been based on point measurements of rainfall (Cao et al., 2011) or gridded surfaces from point observations (Mao et al., 2012). The present study analyzed the trend and relationship between monthly vegetation green- 
ness using the recent rainfall gridded data sets provided by the Climatic Research Unit (CRU).

Soil moisture is defined as the quantity of water contained in soil on a volumetric or gravimetric basis (Magagi and Kerr, 2001). Current methods for obtaining soil moisture data include point measurements (Zehe et al., 2010), model simulations (Fan and van den Dool, 2004), and remote sensing observations (Kerr et al., 2001; Tapley et al., 2004), and many studies have examined the relationship between NDVI and soil moisture (Adegoke and Carleton, 2002; Wang et al., 2007). Because existing soil moisture data is based on site measurements and satellite data, they are impractical for soil moisture estimation at a large scale over a long period. In this study, we used long sequences of simulated soil moisture data to estimate variation in vegetation greenness. The relationships between vegetation greenness and water availability are complicated because of the time lag in the response of vegetation greenness to water availability. Previous studies investigating the potential of using NDVI to estimate rainfall and soil moisture have found correlations between both NDVI and rainfall and NDVI and soil moisture; therefore the NDVI is frequently used to study rainfall and soil moisture (Hellden and Tottrup, 2008; Huber et al., 2011; Fensholt et al., 2012; Gong et al., 2015).

However, few studies have examined the response of vegetation greenness to water availability (both rainfall and soil moisture) in northern China. In this study, we conducted a multi-variable investigation in order to better understand the relationship between vegetation greenness and water availability, as well as their long-term dynamics and trends in northern China. Because soil moisture data were produced by models rather than field data, we focused on rainfall to analyze the greenness and water availability lag factors.

The impact of climate and human activities on vegetation greenness variability is still a matter of debate (Warren, 2005; Hellden and Tottrup, 2008). Nevertheless, NDVI is used as a proxy to study the vegetation greenness response to rainfall variability (Herrmann et al., 2005; Fensholt et al., 2012; Gong et al., 2015), even though rainfall variability is not the only constraining factor for vegetation greenness, and other factors, such as human activities, should also be considered. For this reason, the NDVI residual time series of the NDVI, regressed against rainfall data, was used to study the effect of human activities on vegetation greenness (Herrmann et al., 2005; Huber et al., 2011).

The objective of the present study was to investigate the temporal and spatial trends and relationships between a proxy of vegetation greenness (NDVI), rainfall, and soil moisture in northern China. Specifically, we investigated the extent to which NDVI is related to rainfall at different time lags. Furthermore, NDVI residual time series of the NDVI regressed on rainfall data were used to obtain vegetation greenness trends induced by other factors than water availability.

\section{Materials and methods}

\subsection{AVHRR GIMMS 15-day composite NDVI data}

AVHRR (Advanced Very High Resolution Radiometer), GIMMS (Global Inventory Modeling and Mapping Studies), and NDVI data were used in this study. The NDVI data cover the period from 1982 to 2006 with an $8 \mathrm{~km}$ spatial resolution and biweekly (15 days) temporal frequency. The data were obtained from the website of the Global Land Cover Facility (http://westdc.westgis.ac.cn/ data/1cad1a63-ca8d-431a-b2b2-45d9916d860d). The NDVI data set was carefully assembled from different AVHRR sensors (the AVHRR sensor onboard NOAA satellites 7, 9, 11, 14, 16, and 17) and the spatial resolution of the AVHRR is $1.1 \mathrm{~km}$, and corrected for atmospheric, calibration loss, orbit drift, volcanic eruption, and other effects not related to vegetation change (Tucker et al., 2005). In order to further reduce the influence of clouds, the original 15-day temporal resolution AVHRR GIMMS NDVI data were aggregated monthly by a maximum value composite approach (MVC), increasing the quality of NDVI images by selecting the best observations for each pixel, although the temporal resolution decreases.

\subsection{Rainfall data}

Monthly rainfall products were obtained from the Climatic Research Unit (CRU), University of East Anglia, Norwich, UK. For monthly rainfall, the CRU data set used an interpolation method based on the set of stations available at that moment in time (Mitchell and Jones, 2005). It was provided as a monthly sum at a $0.5^{\circ} \times 0.5^{\circ}$ spatial resolution for the period from 1901 to 2011. Monthly accumulated rainfall data derived from CRU were used from 1981 to 2006 . The CRU data set is appropriate for our study since it is has been used successfully in many studies and is close in resolution to GIMMS and NDVI data (Hellden and Tottrup, 2008; Piao et al., 2011).

\subsection{Soil moisture data}

We used the NOAA National Centers for Environmental Predictions (NCEP) Climate Prediction Center (CPC) monthly high-resolution global soil moisture data set at a $0.5^{\circ}$ spatial resolution for the period from 1982 to 2006 (Fan and van den Dool, 2004). Soil moisture data sets were produced using a one-layer "bucket" water balance model covering the period from 1948 to present. This model used over 17000 gauges worldwide obtained monthly from the Climate Prediction Center (CPC). Global rainfall and monthly global temperatures were obtained from the CDAS-Reanalysis product over land (Kistler et al., 2001; Chen et al., 2002). 


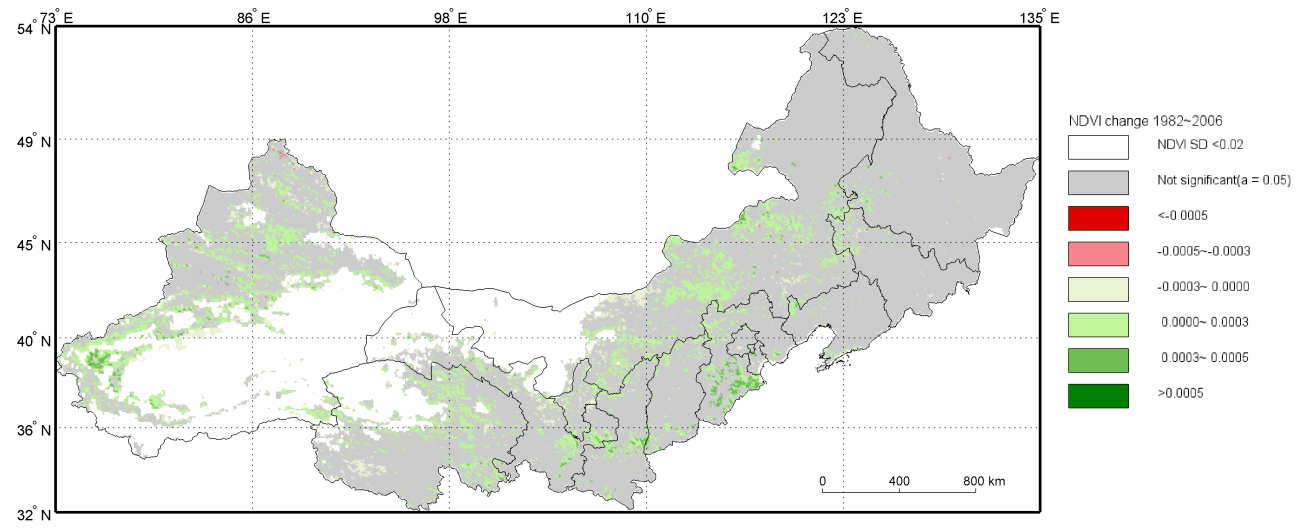

Figure 1. Map of monthly NDVI trend analysis (1982-2006).

\subsection{Data pre-processing}

The analysis was restricted to include only those parts of the study area that had a long-term (1982-2006) monthly NDVI standard deviation (SD) value $<0.02$ (Fensholt and Proud, 2012). Per-pixel QA information in the AVHRR GIMMS NDVI product was used to remove the NDVI data without confidence (contaminated by cloud or snow/ice). Then, a simple temporal filter was applied to fill in the gaps in the missing data and to integrate the AVHRR, GIMMS, and NDVI data (Xiao et al., 2003; Fensholt et al., 2009). In addition, rainfall and soil moisture data with a $0.5^{\circ}$ resolution were resampled into a geographic type of approximately $8 \mathrm{~km} \times 8 \mathrm{~km}$ resolution so that it would match the NDVI.

\subsection{Methods for trend analysis}

The trend of monthly NDVI, rainfall, and soil moisture was obtained from a median trend (Theil-Sen) procedure for the period from 1982 to 2006 (Theil, 1950; Sen, 1968). Trend analyses were employed for NDVI, rainfall, and soil moisture data using Sen's method to investigate how they changed across the study area from 1982 to 2006. Only areas of significant change at $95 \%$ confidence were shown. A linear regression analysis was carried out with NDVI as the dependent variable and 3-monthly cumulative rainfall as the independent variable. We used the non-parametric MannKendall (MK) method for time series trend analysis since it has been commonly applied to vegetation (Fensholt et al., 2009). A positive slope $(z \geq 1.96)$ represents a significant increase $(\alpha=0.05)$ in NDVI, rainfall, or soil moisture while negative slopes $(z \leq-1.96)$ indicate a significant decrease $(\alpha=0.05)$.

\subsection{Methods for correlation analysis}

In this study, Pearson correlation coefficients were calculated among simultaneous NDVI, lagged rainfall, and simultaneous soil moisture on a pixel-by-pixel basis for two differ- ent time frames: the full year and the growing season (April to October). A linear correlation $(r)$ analysis was applied to study the relations between NDVI/rainfall (1982-2006) and NDVI/soil moisture (1982-2006) data sets. The correlations between both NDVI/rainfall and NDVI/soil moisture were obtained for northern China in order to compare the vegetation greenness response to water availability (rainfall and soil moisture) for both the growing season data and all-year data.

\section{Results and discussions}

\subsection{Trend analysis}

Significant trends in NDVI and annual rainfall were derived (Figs. 1 and 2) for the period from 1982 to 2006.Vegetation greenness increased for the period from 1982 to 2006 in the study area, especially in Shaanxi and Hebei provinces, while there was little decline in vegetation greenness in Xinjiang Province. Over the whole study area, there was a significant positive trend in vegetation greenness at a $5 \%$ significance level (Fig. 1). Consistent with earlier findings, vegetation greenness during the study period (1982-2006) significantly increased in several locations across the study area as illustrated in Fig. 1. The rainfall trend was found to be insignificant (Fig. 2) as well as the correlation coefficient map between both NDVI and rainfall and NDVI and soil moisture (Fig. 3) in the growing season.

According to Fig. 3a and b, the significant correlations calculated from all-year data yielded more pixels than the data from only the growing season. A significant positive correlation (0.6-1.0) between NDVI and rainfall was found in large areas over the entire year, but only for a relatively limited area in the growing season (Fig. 3a and b).

The rainfall trend only exhibited a significant increase in western Xinjiang. Large areas in northern China did not exhibit any significant trend in rainfall at a $5 \%$ significance level over the last 25 years (Fig. 2a). Soil moisture in most areas changed significantly, with significant increases in ar- 

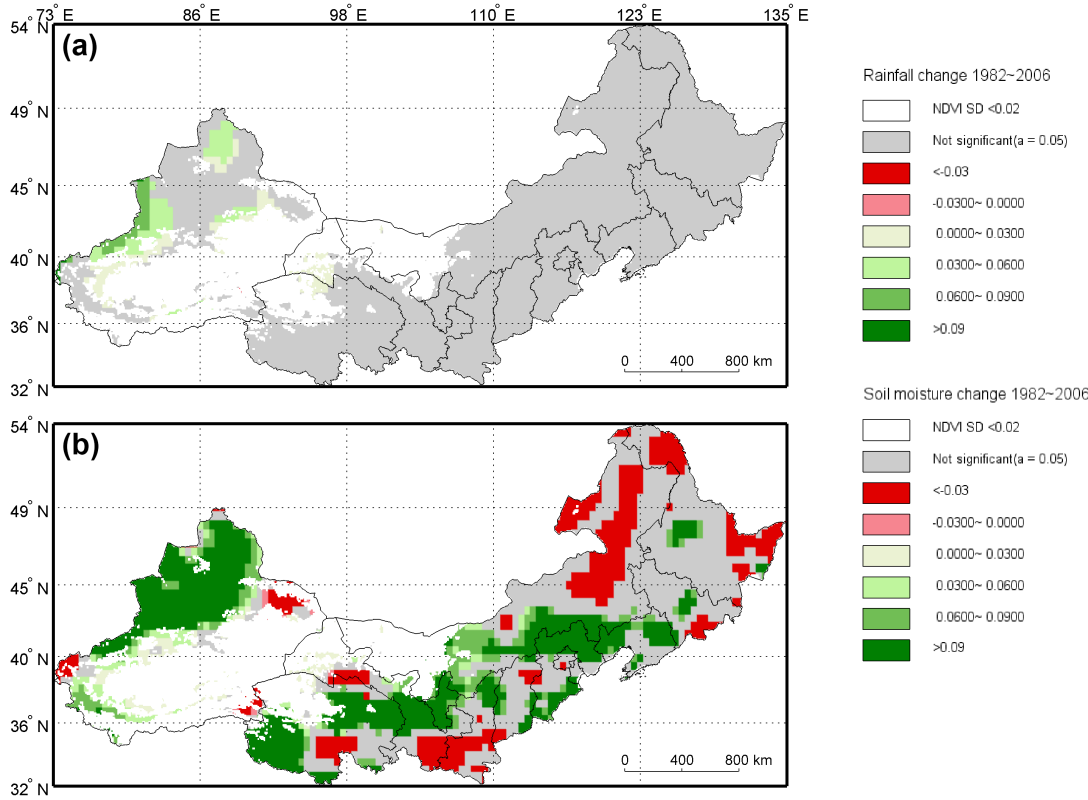

Figure 2. Trend maps for (a) 3-month rainfall sum for all months per year and (b) monthly soil moisture data from 1982 to 2006.
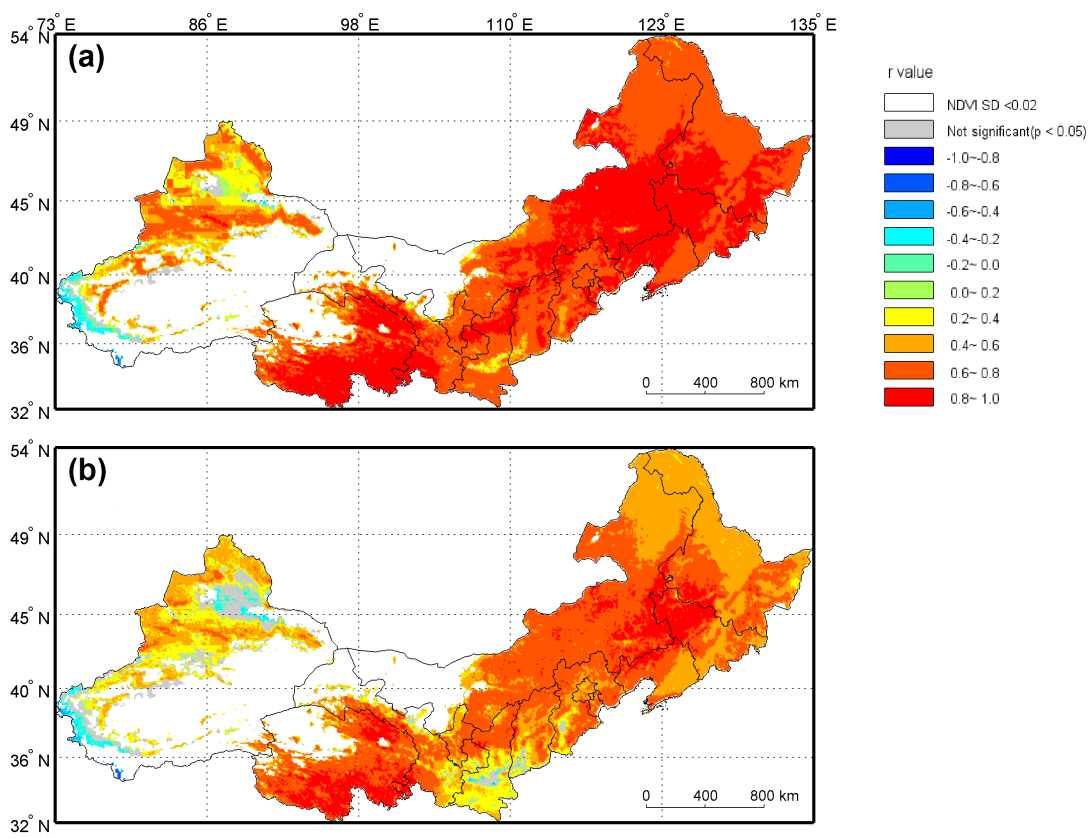

Figure 3. Linear correlation between monthly NDVI and (a) 3-month sums of rainfall for all months per year and (b) 3-month sums of rainfall for the growing season (GS).

eas distributed in Liaoning, Hebei, Qinghai, and Xinjiang provinces, while decreasing significantly in the northern part of Inner Mongolia (Fig. 2b).

The NDVI trends mapped in this study are similar in spatial variability to those reported by Huang et al. (2012) in their study from 1982 to 2007 as both studies used the "TheilSen method" for estimating the NDVI changes (Yin et al., 2011; Huang et al., 2012). Also, the spatial pattern of the positive trends covering a similar time span (1982-2006) is consistent with the results of Hellden et al. (2008), Piao et al. (2011), Fensholt et al. (2012) and Mao et al. (2012). However, it is difficult to compare this trend analysis with other studies because of differences in analytical techniques, significance levels, study periods, and so forth. Most previous research has been based on the NDVI, summed either annually or over the growing season, over relatively short peri- 

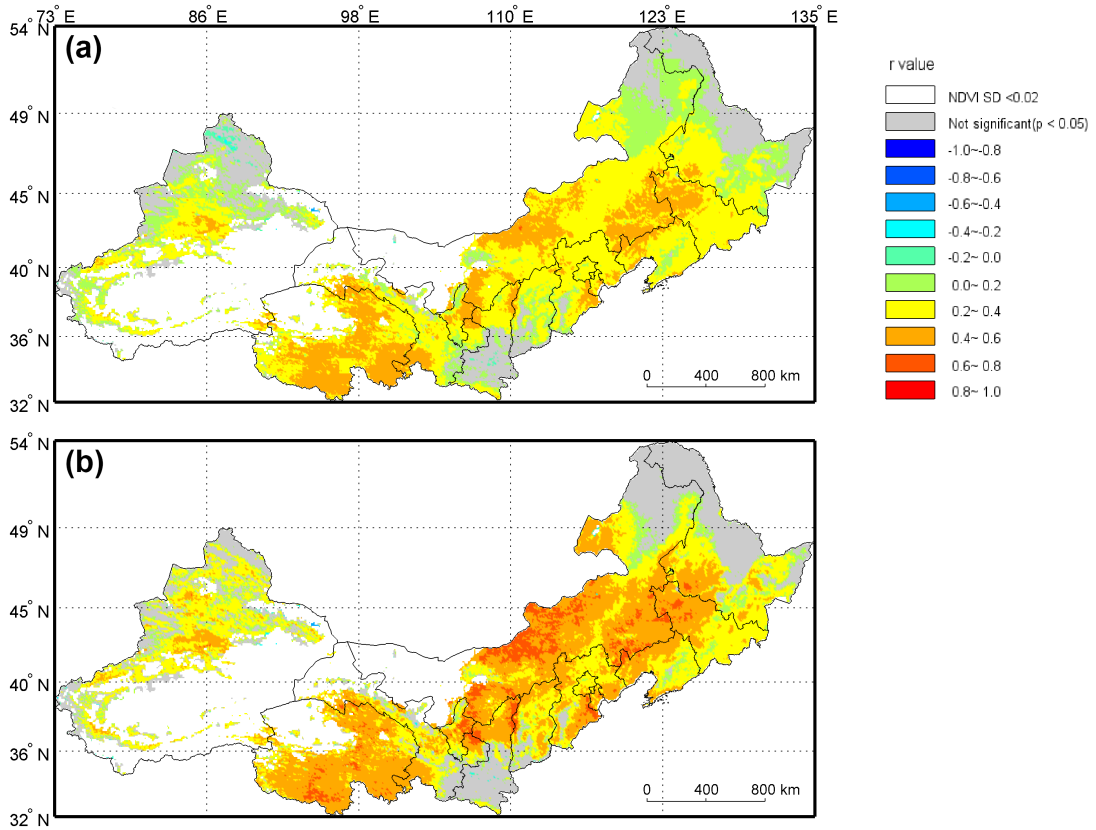

Figure 4. Linear correlation of monthly NDVI and (a) soil moisture for the entire year and (b) soil moisture for the growing season (GS).
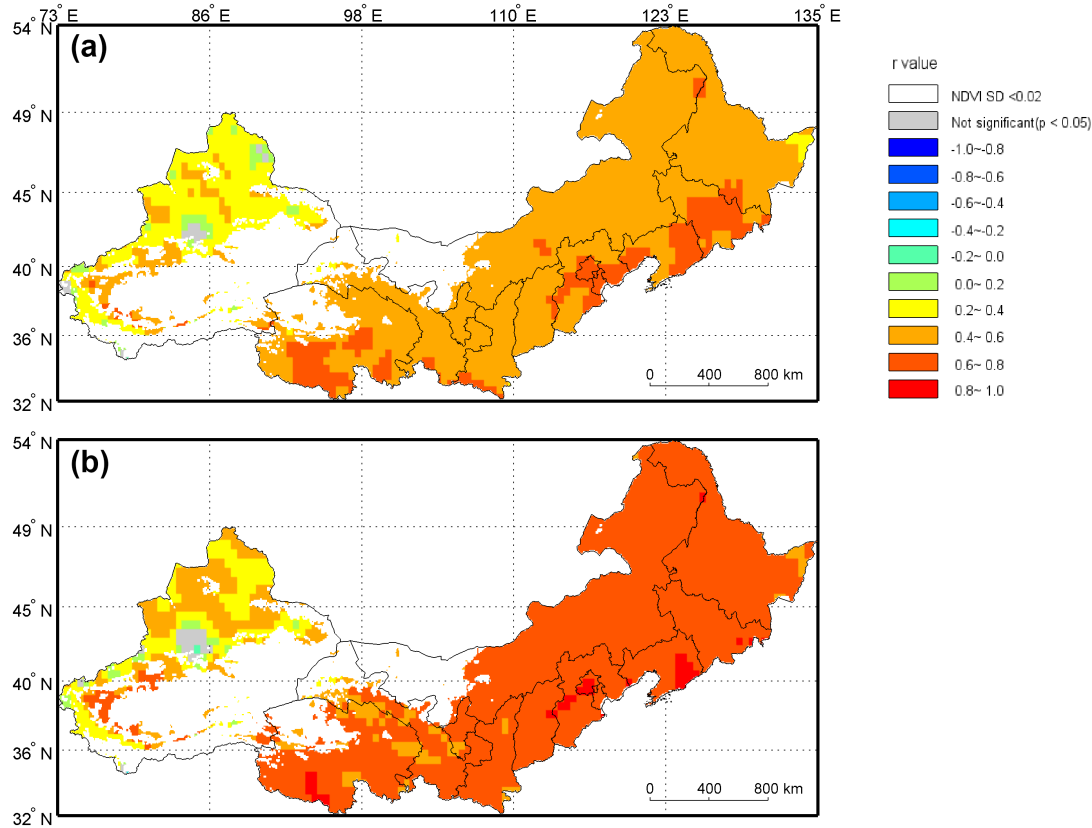

Figure 5. Linear correlation of 3-month sums of rainfall and (a) soil moisture for the entire year and (b) soil moisture for the growing season (GS).

ods, whereas in this study our analysis was based on monthly NDVI over a much longer period from 1982 to 2006. Vegetation greenness trends showed a persistent increase in all study areas. These trends in Shaanxi and Hebei provinces could be related to forest vegetation cover characterized by deep roots, which are able to reach the water table independent of fluctuation in rainfall and soil moisture (Do et al., 2008).

\subsection{Correlations analysis}

All correlation coefficients $(r)$ between NDVI and water availability were statistically significant at $95 \%$ confidence intervals. The relationship analysis was conducted in order to determine the relationship between NDVI and rainfall data for different lag times $(0,1,2$ months of rainfall lags from 
NDVI data) in the study period (Huber et al., 2011). Rainfall exhibited a small correlation with simultaneous NDVI over 25 years; however, the time-lagged NDVI increased their correlation. Three integrated monthly rainfall time series exhibited a better correlation with monthly NDVI. The 3-monthsummed rainfall and NDVI data correlation analysis was then performed (Figs. 3 and 4).

Figure 4 presents the correlations ( $r$ values) between the monthly NDVI and soil moisture for the entire year and the growing season in northern China. The growing season, from April to October, had the highest correlation between NDVI and soil moisture in the study area.

Correlations between the 3-month sums of monthly rainfall and soil moisture for both the entire year and the growing season in northern China are shown in Fig. 5. In most parts of the study area, rainfall and soil moisture during the growing season is better than for the full year.

Correlations for both the entire year and the growing season decreased in most of the study area when the 3month-summed time lag between NDVI and rainfall was analyzed, suggesting that NDVI was more responsive to the 3month sum than for the entire year. Several previous studies have documented a similar correlation distributed in northern China since the early 1980s (Hellden and Tottrup, 2008; Huang et al., 2012; Mu et al., 2012). Grassland phenology dynamics are closely related to spring precipitation and increasing temperature at the early growing period (Gong et al., 2015). Also, the vegetation changes are affected by other factors, such as anthropogenic activity (Kou et al., 2015; Russell and Ward, 2016).

Many studies applied remote sensing data to investigate the spatial variation of the vegetation greenness events and the relation to water availability by using the same methods (Gong et al., 2015; Holleran et al., 2015; Kaiser et al., 2015; Zucca et al., 2015). Plants are important in the Earth system (Lieskovsky and Kenderessy, 2014; Berendse et al., 2015; Cassinari et al., 2015; Poelking et al., 2015; Beyene, 2015; Zhao et al., 2015). The weaker correlation between NDVI and soil moisture for the entire year might be explained by the large column depth $(1.6 \mathrm{~m})$ used to model soil moisture data (Fan and van den Dool, 2004). However, the correlation between NDVI and soil moisture during the growing season is higher than for the entire year (Fig. 4a and b). Fensholt et al. (2010) showed that soil moisture in the upper $20-30 \mathrm{~cm}$ had a high correlation with shorter plant roots. The results indicate that NDVI and soil moisture had higher statistically significant correlations in the growing season, indicating that NDVI had a stronger response to soil moisture variation.

\section{Conclusions}

This study has evaluated the trends and correlations between NDVI, soil moisture, and lagged rainfall data during the observation period (1982-2006). Vegetation greenness and soil moisture have significantly changed in the whole study area, while rainfall remained unchanged. This study showed that NDVI is strongly correlated to simultaneous soil moisture and lagged rainfall during the growing season. Rainfall and soil moisture both exhibited similar relationships with NDVI, suggesting that NDVI is appropriate for monitoring vegetation greenness response to water availability in northern China from 1982 to 2006. The results of this study have important implications for improving our understanding of the relationship between vegetation greenness and water availability in northern China.

\section{Data availability}

AVHRR GIMMS NDVI data cover the period from 1982 to 2006 with an $8 \mathrm{~km}$ spatial resolution, and biweekly (15 days) temporal frequency was obtained from the website of the WestDC (http://westdc.westgis.ac.cn/data/ 1cad1a63-ca8d-431a-b2b2-45d9916d860d) (Tucker et al., 2005). Monthly rainfall products were obtained from the Climate Research Unit (CRU), University of East Anglia, Norwich, UK (http://browse.ceda.ac.uk/browse/badc/ cru/data) (Mitchell and Jones, 2005). The NOAA National Centers for Environmental Predictions (NCEP) Climate Prediction Center (CPC) monthly high-resolution global soil moisture data set at a 0.5 spatial resolution for the period from 1982 to 2006 was used (http://www.cpc.ncep.noaa.gov/ soilmst/leaky_glb.htm) (Fan and van den Dool, 2004).

Acknowledgements. This paper was supported by the Open Research Funding Program of KLGIS (KLGIS2015A03); the Science and Technology Fund of Guizhou Province, China (grant no. [2015]2118); Scientific Research Starting Fund for Doctor of Guizhou Normal University. The authors would like to thank the GIMMS (the NASA Global Inventory Modeling and Mapping Studies) group for sharing the GIMMS NDVI data. We would also like to thank the anonymous reviewers for their comments, which greatly improved this manuscript.

Edited by: A. Cerdà

\section{References}

Adegoke, J. O. and Carleton, A. M.: Relations between Soil Moisture and Satellite Vegetation Indices in the US Corn Belt, J. Hydrometeorol., 3, 395-405, 2002.

Beyene, S. T.: Rangeland degradation in a Semi-Arid communal savannah of Swaziland: Long-Term DIP-tank use effects on woody plant structure, cover and their indigenous use in three soil types, Land Degrad. Dev., 26, 311-323, 2015.

Berendse, F., van Ruijven, J., Jongejans, E., and Keesstra, S.: Loss of plant species diversity reduces soil erosion resistance, Ecosystems, 18, 881-888, 2015. 
Bochet, E.: The fate of seeds in the soil: a review of the influence of overland flow on seed removal and its consequences for the vegetation of arid and semiarid patchy ecosystems, SOIL, 1, 131-146, doi:10.5194/soil-1-131-2015, 2015.

Brevik, E. C., Cerdà, A., Mataix-Solera, J., Pereg, L., Quinton, J. N., Six, J., and Van Oost, K.: The interdisciplinary nature of SOIL, SOIL, 1, 117-129, doi:10.5194/soil-1-117-2015, 2015.

Cassinari C., Manfredi P., Giupponi L., Trevisan M., and Piccini C.: Relationship between hydraulic properties and plant coverage of the closed-landfill soils in Piacenza (Po Valley, Italy), Solid Earth, 6, 929-943, doi:10.5194/se-6-929-2015, 2015.

Cao, X. M., Chen, X., Bao, A. M., and Wang, Q.: Response of vegetation to temperature and precipitation in Xinjiang during the period of 1998-2009, J. Arid Land, 3, 94-103, 2011.

Cerdà, A.: The influence of aspect and vegetation on seasonal changes in erosion under rainfall simulation on a clay soil in Spain, Can. J. Sci., 78, 321-330, 1998.

Chen, M. Y., Xie, P. P., Janowiak, J. E., and Arkin, P. A.: Global Land Precipitation: A 50-yr Monthly Analysis Based on Gauge Observations, J. Hydrometeorol., 3, 249-266, 2002.

Decock, C., Lee, J., Necpalova, M., Pereira, E. I. P., Tendall, D. M., and Six, J.: Mitigating $\mathrm{N}_{2} \mathrm{O}$ emissions from soil: from patching leaks to transformative action, SOIL, 1, 687-694, doi:10.5194/soil-1-687-2015, 2015.

Do, F. C., Rocheteau, A., Diagne, A. L., Goudiaby, V., Granier, A., and Lhomme, J. P.: Stable annual pattern of water use by Acacia tortilis in Sahelian Africa, Tree Physiol., 28, 95-104, 2008.

Fan, Y. and van den Dool, H.: Climate Prediction Center global monthly soil moisture data set at 0.5 resolution for 1948 to present, J. Geophys. Res., 109, D10102, doi:10.1029/2003JD004345, 2004.

Fensholt, R. and Proud, S. R.: Evaluation of Earth Observation based global long term vegetation trends - Comparing GIMMS and MODIS global NDVI time series, Remote Sens. Environ., 119, 131-147, 2012.

Fensholt, R., Rasmussen, K., Nielsen, T. T., Mbow, C., and Rasmussen, K.: Evaluation of earth observation based long term vegetation trends - Intercomparing NDVI time series trend analysis consistency of Sahel from AVHRR GIMMS, Terra MODIS and SPOT VGT data, Remote Sens. Environ., 113, 1886-1898, 2009.

Fensholt, R., Huber, S., Proud, S. R., and Mbow, C.: Detecting Canopy Water Status Using Shortwave Infrared Reflectance Data From Polar Orbiting and Geostationary Platforms, IEEE JSTARS, 3, 271-285, 2010.

Fensholt, R., Langanke, T., Rasmussen, K., Bondeau, A., and Eastman, R.: Greenness in semi-arid areas across the globe 19812007 - an Earth Observing Satellite based analysis of trends and drivers, Remote Sens. Environ., 121, 144-158, 2012.

Gong, Z., Kawamura, K., Ishikawa, N., Goto, M., Wulan, T., Alateng, D., Yin, T., and Ito, Y.: MODIS normalized difference vegetation index (NDVI) and vegetation phenology dynamics in the Inner Mongolia grassland, Solid Earth, 6, 1185-1194, doi:10.5194/se-6-1185-2015, 2015.

Hellden, U. and Tottrup C.: Regional desertification: A global synthesis, Global Planet. Change, 64, 169-176, 2008.

Hewelke, E., Szatyłowicz, J., Gnatowski, T., and Oleszczuk, R.: Effects of soil water repellency on moisture patterns in a degraded sapric histosol, Land Degrad. Dev., 27, 955-964, doi:10.1002/ldr.2305, 2014.
Herrmann, S. M., Anyamba, A., and Tucker, C. J.: Recent trends in vegetation dynamics in the African Sahel and their relationship to climate, Global Environ. Change, 15, 394-404, 2005.

Holleran, M., Levi, M., and Rasmussen, C.: Quantifying soil and critical zone variability in a forested catchment through digital soil mapping, SOIL, 1, 47-64, doi:10.5194/soil-1-47-2015, 2015.

Huang, S. W., Li, X. S., Wu, B. F., and Pei, L.: The Distribution and Drivers of Land Degradation in the Three-North Shelter Forest Region of China during 1982-2006, Acta Geographica Sinica, 67, 589-598, 2012.

Huber, S., Fensholt, R., and Rasmussen, K.: Water availability as the driver of vegetation dynamics in the African Sahel from 1982 to 2007, Global Planet. Change, 76, 186-195, 2011.

Kaiser, A., Neugirg, F., Haas, F., Schmidt, J., Becht, M., and Schindewolf, M.: Determination of hydrological roughness by means of close range remote sensing, SOIL, 1, 613-620, doi:10.5194/soil-1-613-2015, 2015.

Keesstra, S. D., Geissen, V., van Schaik, L., Mosse., K., and Piiranen, S.: Soil as a filter for groundwater quality, Current Opinions in Environmental Sustainability, 4, 507-516, 2012.

Keesstra, S. D., Bouma, J., Wallinga, J., Tittonell, P., Smith, P., Cerdà, A., Montanarella, L., Quinton, J. N., Pachepsky, Y., van der Putten, W. H., Bardgett, R. D., Moolenaar, S., Mol, G., Jansen, B., and Fresco, L. O.: The significance of soils and soil science towards realization of the United Nations Sustainable Development Goals, SOIL, 2, 111-128, doi:10.5194/soil-2-1112016, 2016a.

Keesstra, S. D., Pereira, P., Novara, A., Brevik, E. C., AzorinMolina, C., Parras-Alcantara, L., Jordan, A., and Cerdà, A.: Effects of soil management techniques on soil water erosion in apricot orchards, Sci. Total Environ., 551-552, 357-366, doi:10.1016/j.scitotenv.2016.01.182, 2016b.

Kerr, Y. H., Waldteufel, P., and Wigneron, J. P.: Soil moisture retrieval from space: the Soil Moisture and Ocean Salinity (SMOS) mission, IEEE T. Geosci. Remote, 39, 1729-1735, 2001.

Kistler, R., Collins, W., Saha, S., White, G., Woollen, J., and Kalnay, E.: The NCEP-NCAR 50-Year Reanalysis:Monthly Means CDROM and Documentation, B. Am. Meteorol. Soc., 82, 247-267, 2001.

Kou, M., Jiao, J., Yin, Q., Wang, N., Wang, Z., Li, Y., Yu, W., Wei, Y., Yan, F., and Cao, B.: Successional Trajectory Over 10 Years of Vegetation Restoration of Abandoned Slope Croplands in the Hill-Gully Region of the Loess Plateau, Land Degrad. Dev., 379 125-135, doi:10.1002/ldr.2356, 2015.

Laberge, V., Hugron, S., Rochefort, L., and Poulin, M.: Influence of Different Bryophyte Carpets on Vascular Plant Establishment Around Pools in Restored Peatlands, Land Degrad. Dev., 26, 813-818, 2015.

Lieskovsky, J. and Kenderessy, P.: Modelling the effect of vegetation cover and different tillage practices on soil erosion in: A case study in vráble (Slovakia) using WATEM/SEDEM, Land Degrad. Dev., 25, 288-296, 2014.

Lucas-Borja, M. E., Hedo de Santiago, J., Candel-Pérez, D., Cerdá, A., and Viñegla, B.: Unravelling the importance of forest age stand and forest structure driving microbiological soil properties, enzymatic activities and soil nutrients content in Mediterranean Spanish Black Pine (Pinus nigra Ar. ssp. salzmannii) Forest, Sci Total Environ., 562, 145-154, doi:10.1016/j.scitotenv, 2016. 
Magagi, R. D. and Kerr, Y. H.: Estimating surface soil moisture and soil roughness over semiarid areas from the use of the copolarization ratio, Remote Sens. Environ., 75, 432-445, 2001.

Mao, D. H., Wang, Z. M., Luo, L., and Ren, C.: Integrating AVHRR and MODIS data to monitor NDVI changes and their relationships with climatic parameters in Northeast China, Int. J. Appl. Earth Obs., 18, 528-536, 2012.

Mitchell, T. D. and Jones, P. D.: An improved method of constructing a database of monthly climate observations and associated high - resolution grids, Int. J. Climatol., 25, 693-712, 2005.

Mu, S. J., Li, J. L., Chen, Y. J., Gang, C., Zhou, W., and Weimin, J. U.: Spatial Differences of Variations of Vegetation Coverage in Inner Mongolia during 2001-2010, Acta Geographica Sinica, 69, 1255-1268, 2012.

Niu, C. Y., Musa, A., and Liu, Y.: Analysis of soil moisture condition under different land uses in the arid region of Horqin sandy land, northern China, Solid Earth, 6, 1157-1167, doi:10.5194/se6-1157-2015, 2015.

Piao, S. L., Wang, X. H., Ciais, P., Zhu, B., Wang, T., and Liu, J.: Changes in satellite-derived vegetation growth trend in temperate and boreal Eurasia from 1982 to 2006, Glob. Change Biol., 17, 3228-3239, 2011.

Poelking, E. L., Schaefer, C. E. R., Fernandes Filho, E. I., De Andrade, A. M., and Spielmann, A. A.: Soil-landform-plantcommunity relationships of a periglacial landscape on Potter Peninsula, maritime Antarctica, Solid Earth, 6, 583-594, doi:10.5194/se-6-583-2015, 2015.

Russell, J. M. and Ward, D.: Historical Land-use and Vegetation Change in Northern Kwazulu-Natal, South Africa, Land Degrad. Dev., doi:10.1002/ldr.2476, 2016.

Sen, P. K.: Estimates of regression coefficient based on Kendalls Tau, J. Am. Stat. Assoc., 63, 1379-1389, 1968.

Smith, P., Cotrufo, M. F., Rumpel, C., Paustian, K., Kuikman, P. J., Elliott, J. A., McDowell, R., Griffiths, R. I., Asakawa, S., Bustamante, M., House, J. I., Sobocká, J., Harper, R., Pan, G., West, P. C., Gerber, J. S., Clark, J. M., Adhya, T., Scholes, R. J., and Scholes, M. C.: Biogeochemical cycles and biodiversity as key drivers of ecosystem services provided by soils, SOIL, 1, 665685, doi:10.5194/soil-1-665-2015, 2015,

Tapley, B. D., Bettadpur, S., Ries, J. C., Thompson, P. F., and Watkins, M. M.: GRACE Measurements of Mass Variability in the Earth System, Science, 305, 503-505, 2004.

Theil, H.: A rank-invariant method of linear and polynomial regression analysis, Proceedings of the Royal Netherlands Academy of Sciences, 53, 386-392, 1950.
Tucker, C. J., Pinzon, J. E., Brown, M. E., Slayback, D. A., Pak, E. W., Mahoney, R., Vermonte, E. F., and El Saleous, N.: An extended AVHRR $8 \mathrm{~km}$ - NDVI dataset compatible with MODIS and SPOT vegetation NDVI data, Int. J. Remote Sens., 26, 44854498, doi:10.1080/01431160500168686, 2005.

Vaezi, A. R., Hasanzadeh, H., and Cerdà, A.: Developing an erodibility triangle for soil textures in semi-arid regions, NW Iran, Catena, 142, 221-232, 2016.

Wang, X., Xie, H., Guan, H., and Zhou, X.: Different responses of MODIS-derived NDVI to root-zone soil moisture in semi-arid and humid regions, J. Hydrol., 340, 12-24, 2007.

Warren, A.: The policy implications of Sahelian change, J. Arid Environ., 63, 660-670, 2005.

Xiao, X. M., Braswell, B., Zhang, Q. Y., Boles, S., Frolking, S., and Iii, B. M.: Sensitivity of vegetation indices to atmospheric aerosols, continental-scale observations in Northern Asia, Remote Sens. Environ., 84, 385-392, 2003.

Yin, H., Guo, L. Z., Lin, W. Y., and Cai, F.: Assessment of Desertification Using Time Series Analysis of Hyper-temporal Vegetation Indicator in Inner Mongolia, Acta Geographica Sinica, 66, 653661, 2011.

Yu, Y. and Jia, Z. Q.: Changes in soil organic carbon and nitrogen capacities of Salix cheilophila Schneid along a revegetation chronosequence in semi-arid degraded sandy land of the Gonghe Basin, Tibetan Plateau, Solid Earth, 5, 1045-1054, doi:10.5194/se-5-1045-2014, 2014.

Yu, Y., Wei, W., Chen, L. D., Jia, F. Y., Yang, L., Zhang, H. D., and Feng, T. J.: Responses of vertical soil moisture to rainfall pulses and land uses in a typical loess hilly area, China, Solid Earth, 6, 595-608, doi:10.5194/se-6-595-2015, 2015.

Zehe, E., Graeff, T., Morgner, M., Bauer, A., and Bronstert, A.: Plot and field scale soil moisture dynamics and subsurface wetness control on runoff generation in a headwater in the Ore Mountains, Hydrol. Earth Syst. Sci., 14, 873-889, doi:10.5194/hess14-873-2010, 2010.

Zhang, X. Y., Goldberg, M., Tarpley, D., Friedl, M. A., Morisette, J., and Kogan, F.: Drought-induced vegetation stress in southwestern North America, Environ. Res. Lett., 5, 302-307, 2010.

Zhao, C., Gao, J., Huang, Y., Wang, G., and Zhang, M.: Effects of Vegetation Stems on Hydraulics of Overland Flow Under Varying Water Discharges, Land Degrad. Dev., 27, 748-757, doi:10.1002/ldr.2423, 2015.

Zucca, C., Wu, W., Dessena, L., and Mulas, M.: Assessing the Effectiveness of Land Restoration Interventions in Dry Lands by Multitemporal Remote Sensing - A Case Study in Ouled DLIM (Marrakech, Morocco), Land Degrad. Dev., 26, 80-91, 2015. 